\title{
INFLUÊNCIA DO ÂNGULO DE FOLGA E FLUIDO DE CORTE NA USINABILIDADE DO AÇO ABNT I045 UTILIZANDO O MÉTODO FACEAMENTO RÁPIDO DE BRANDSMA
}

André Alves de Resende ' Leandro de Lima Ramaldes ' Ana Luíza Ferreira Mamede '

Ricardo Ribeiro Moura '

Marco Paulo Guimarães '

\section{Resumo}

Usinabilidade de um material demonstra como ele se comporta frente a diferentes condições de usinagem. É influenciado por vários fatores como a geometria da ferramenta e o uso de fluídos de corte. O método de Faceamento Brandsma é um ensaio de curta duração que permite avaliar o comportamento de uma ferramenta até atingir o colapso. O objetivo deste trabalho é utilizar o método de Brandsma para analisar a influência do ângulo de folga e do uso de fluído de corte sobre a usinabilidade do aço ABNT 1045. Para tanto, foram realizados testes com e sem fluído comparando e avaliando o comportamento de ângulos de folga de $2^{\circ}, 4^{\circ}, 6^{\circ}, 8^{\circ}$ e $10^{\circ}$, observando com isso que o aumento do ângulo de folga proporciona um aumento no percurso de usinagem e, finalmente, a presença do fluido de corte aumenta o percurso de corte para todos os valores de ângulo de folga.

Palavras-chave: Usinabilidade; Brandsma; Ângulo de folga; Fluído de corte.

\section{INFLUENCE OF CLEARANCE ANGLE AND CUT FLUID IN THE ABNT I045 USINABILITY USING BRANDSMA METHOD}

\begin{abstract}
Machinability of a material demonstrates how it behaves against different machining conditions. It is influenced by factors such as tool geometry and use of cutting fluids. The Brandsma Facing method is a short duration test that allows evaluating the behavior of a tool until it reaches collapse. The test can be performed under different conditions quickly and efficiently. Therefore, this work aim to use the method to analyze the influence of the angle of slack and the use of cutting fluid on the machinability of ABNT 1045 steel. For that, tests with and without fluid were performed comparing the behavior of clearance angles of $2^{\circ}, 4^{\circ}, 6^{\circ}, 8^{\circ}$ and $10^{\circ}$. As main results it was observed that for the range of values evaluated, the increase in the clearance angle provides an increase in the machining path, and the presence of the cutting fluid increases the cutting distance for all conditions.
\end{abstract}

Keywords: Machinability; Brandsma; Clearance angle; Cutting fluid.

\section{INTRODUÇÃO}

Segundo Trent e Wright [I], a usinabilidade não é uma propriedade, mas o modo que o material se comporta durante a usinagem. Já Ferraresi [2], incrementa que a usinabilidade não é uma grandeza física específica de um dado material, tal como a resistência à tração, o alongamento ou o módulo de elasticidade, mas sim uma propriedade global, resultante da combinação do material da peça e da ferramenta de corte.
Os resultados de ensaios de usinabilidade interessam tanto para os fabricantes de materiais como para fabricantes de ferramenta e o consumidor final. Esses resultados tem um papel importante na produtividade do segmento metalúrgico. Todos os processos de engenharia envolvidos no desenvolvimento de novas geometrias de ferramentas de corte e de novas ligas de materiais, bem como os tratamento superficiais, se baseiam nestes ensaios de usinabilidade.

'Unidade Acadêmica Especial de Engenharia, Universidade Federal de Goiás - UFG, Catalão, GO, Brasil. email: aaresende@gmail.com 
Segundo Diniz et al. [3], existem outros fatores, além do material a ser usinado bem como o tipo de ferramenta utilizada no processo de usinagem. Características de rigidez do sistema máquina-dispositivo-ferramenta-peça e sistema de refrigeração são fatores que interagem diretamente com o fator usinabilidade.

Ferraresi [2] acrescenta ainda que outros fatores estão diretamente ligados à influência na usinabilidade dos metais, dividindo-os em 3 características: Material da peça: composição química, dureza, tensão residual; Processo mecânico: parâmetros de corte, fluido de refrigeração, material da ferramenta; Condições de usinagem: rigidez do sistema porta ferramenta, rigidez da máquina, potência disponível, condições de corte (corte interrompido ou constante), e condições de saída do cavaco.

Assim, se faz necessário utilizar procedimentos capazes de identificar e quantificar o quanto a variação dos diferentes parâmetros de usinagem afetam a usinabilidade de um determinado material. $O$ destaque fica para os testes de vida, que buscam quantificar o tempo de usinagem para cada condição de corte, podem ser de longa duração (realizado em condições próximas às reais de usinagem) ou de curta duração (condições mais severas para reduzir o tempo do teste). Silveira [4] afirma que ensaios de vida de curta duração foram criados como alternativa aos ensaios de vida de longa duração, com a finalidade de se atingir o critério de fim de vida da ferramenta de corte de forma mais rápida e econômica. Estes ensaios consistem em trabalhar com altas velocidades de corte impondo à ferramenta um degaste por difusão, reduzindo o tempo de vida da ferramenta.

Um dos métodos de ensaios de vida de curta duração, o método de faceamento de Brandsma, consiste em facear um disco do centro para periferia, com rotação fixa e velocidade de corte variando durante o percurso de faceamento. Inicia-se com uma velocidade pequena e chega-se a uma velocidade limite, definida pela falha da aresta de corte [2].

Sendo assim, o objetivo deste trabalho é fazer o ranqueamento, por meio do faceamento rápido de Brandsma, de ferramentas de aço rápido afiadas com diferentes ângulos de folga na usinagem do aço ABNT 1045 nas condições a seco e com fluido de corte.

A realização deste trabalho se justifica uma vez que os resultados podem servir como parâmetro, tanto para a indústria quanto para o meio acadêmico, no processo de seleção dos ângulos adequados para usinar o aço ABNT 1045 com ferramentas de aço rápido.

\section{I Usinabilidade}

Segundo Pereira [5], um dos fatores mais importantes para se avaliar a usinabilidade de um material é a vida da ferramenta, pois é ela que determina a interrupção do processo. A vida de uma ferramenta de corte tem fim, na maioria das vezes, devido ao aumento dos desgastes que nela operam, sendo que os principais são os desgastes de entalhe, de flanco e de cratera. Entre esses, o desgaste mais comum é o de flanco, que acontece na superfície de folga da ferramenta devido $o$ atrito entre a ferramenta e a peça.

Outro fator que influencia na usinabilidade de um material é a utilização ou não de fluidos de corte. Segundo Oliveira e Alves [6], é muito comum o uso de fluidos de corte nos processos de usinagem por causa da melhora nas condições tribológicas. Seu uso minimiza a geração de calor, aumenta a vida da ferramenta, ajuda na remoção dos cavacos e, na maioria das vezes, melhora a eficiência do sistema produtivo. Porém, devido aos seus efeitos negativos, como o dano ao meio ambiente, o seu uso só é viável se o tempo de vida da ferramenta, o tempo de usinagem e a qualidade superficial da peça forem maiores que os obtidos com a usinagem sem fluido.

\section{I.2 Geometria da Ferramenta de Corte}

Um dos fatores de extrema importância que influenciam na usinabilidade de um material é a geometria da ferramenta, pois por menores que sejam, alterações dimensionais e angulares podem causar resultados distintos [3]. Porém, a baixa usinabilidade em relação a um critério não significa, necessariamente, que $\circ$ material terá baixa usinabilidade em relação a outros critérios [7].

Em uma ferramenta de corte também devem prevalecer as características relevantes em sua construção, tais como alta dureza em elevadas temperaturas, alta resistência mecânica e ao desgaste, alta tenacidade, alta resistência ao choque térmico, à compressão e elevada estabilidade química [3].

Os elementos da geometria cortante podem ser combinados e caracterizados como: ângulo de folga $(\alpha)$;

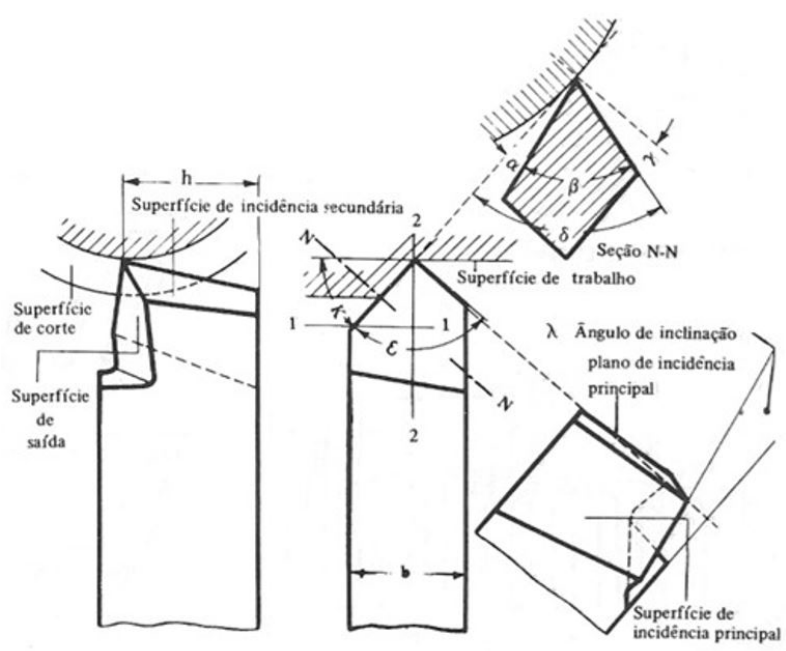

Figura I. Ângulos aplicados em uma ferramenta de corte. Fonte: Chieco [8]. 
ângulo da cunha $(\beta)$; ângulo de saída $(\gamma)$; ângulo de corte $(\delta)$; ângulo de posição ou de rendimento ( $\kappa)$; ângulo da ponta ou de perfil $(\varepsilon)$; ângulo de inclinação $(\lambda)$. Na Figura I, são ilustrados estes ângulos.

Machado et al. [9] afirmam que o ângulo de saída tem influência direta na força e potência que originam o corte, no acabamento superficial e no aquecimento gerado no sistema de corte. Wertheim et al. [10] afirmam que para ângulos de saída de no máximo $25^{\circ}$ nas pastilhas utilizadas durante processo de fresamento, proporciona deformações do cavaco no processo, minimizando as forças de corte e propiciando melhores índices de usinabilidade.

Para Kaldor e Malkin [I I], o ângulo de folga é um dos mais importantes na geometria da ferramenta de corte, e, normalmente, apresenta um valor ideal que proporciona uma vida máxima da ferramenta. Abaixo deste valor é observado um desgaste por abrasão no flanco, acima deste valor, o desgaste normalmente é acompanhado por quebras ou lascamentos da ferramenta.

Cui et al. [12], observou que quando o ângulo de folga aumenta, o valor da força suportada pela ferramenta diminui, indicando que é provável que uma maior área de fratura aconteça na face do flanco. Para o autor, o ângulo de folga menor parece ser a melhor escolha para evitar fraturas na face do flanco da ferramenta.

\section{I.3 Método de faceamento de Brandsma}

O processo de faceamento de Brandsma é um torneamento radial em que a ferramenta se desloca seguindo uma trajetória retilínea, perpendicular ao eixo principal de rotação da máquina, visando obter uma superfície plana [2]. $O$ teste é finalizado quando a ferramenta falha.

O método de faceamento de Brandsma é agrupado por Ferraresi [2] nos critérios baseados na vida da ferramenta. Trata-se de um ensaio de curta duração em que se realiza o faceamento de um disco, usando avanço e rotação constantes, do centro para a periferia, iniciando com uma velocidade pequena e chegando a uma velocidade bem maior, delimitada pelo surgimento da queima da aresta cortante.

\section{MATERIAIS E MÉTODOS}

Utilizando um disco de aço ABNT $1045(25 \mathrm{~mm}$ de espessura, diâmetro externo de $250 \mathrm{~mm}$, com um furo de diâmetro de $19,7 \mathrm{~mm}$ ), conforme Figura 2, e, tendo o método de Brandsma como referência, foram realizados experimentos para diferentes ângulos de folga de $2^{\circ}, 4^{\circ}$, $6^{\circ}, 8^{\circ}$ e $10^{\circ}$, na condição com fluido de corte e sem fluido de corte, sendo realizados dois ensaios para cada condição, o que resultou na realização de 20 (vinte) experimentos.

Para a condução dos ensaios, foi utilizado um torno mecânico Mascoti Nardini MS-205 com potência disponível de 6,3 cv. Os parâmetros gerais utilizados foram:

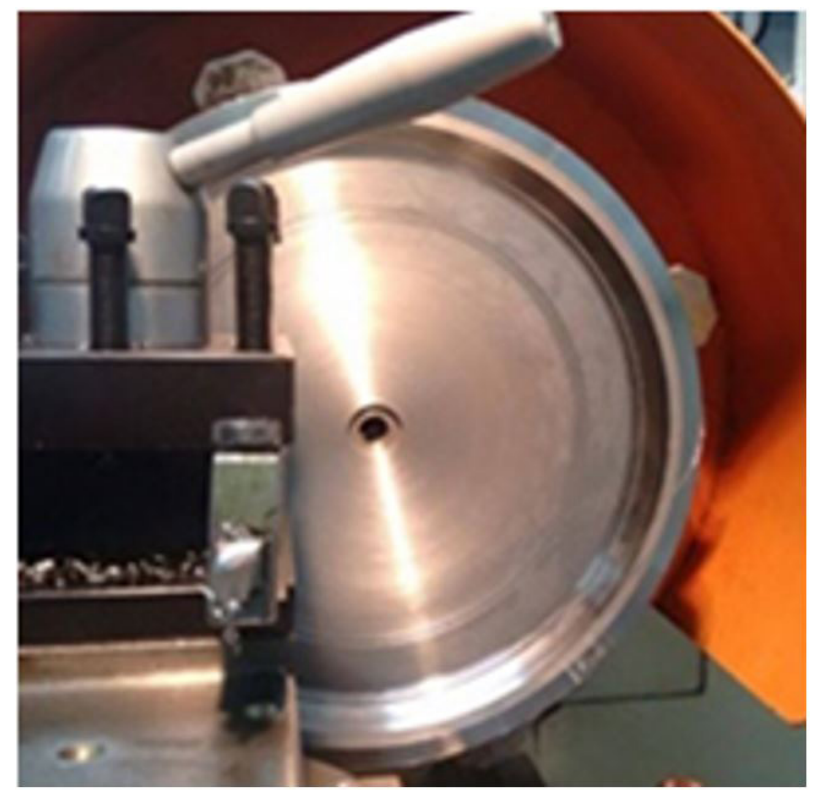

Figura 2. Disco de aço ABNT 1045 utilizado nos testes.

- Rotação da peça (n): 315 rpm;

- Profundidade de corte (a): 0,4 mm;

- Avanço por rotação (f): 0,079 mm/rotação;

- Ângulo de posição $(\lambda)$ : $45^{\circ}$;

- Ângulo de Saída $(\gamma)$ : 18;

- Ângulo de cunha $(\beta): 64^{\circ}$;

- Ângulo de folga $(\alpha): 2^{\circ}, 4^{\circ}, 6^{\circ}, 8^{\circ}$ e $10^{\circ}$.

A escolha das ferramentas foi baseada nos estudos de Araujo et al. [13], que afirma que nos ensaios de usinabilidade de curta duração o material para ferramenta mais usado é o aço rápido (HSS - High Speed Steel). As ferramentas que foram usadas nos testes são de aço rápido, sendo bits na seção quadrada de $3 / 8$ " de polegadas $(9,525 \mathrm{~mm}) \mathrm{HSS}$ - $10 \% \mathrm{CO}$ (aço rápido com $10 \%$ de cobalto). Estas ferramentas foram afiadas com geometria favorável ao desgaste, com ângulo de saída de $18^{\circ}$, ângulo de cunha de $64^{\circ}$ e ângulo de folga variando para os valores já citados. Para facilitar a etapa experimental, foram afiadas $10(\mathrm{dez})$ ferramentas diferentes e realizados, de forma aleatória, todos os testes sem fluido de corte. Posteriormente, as ferramentas foram reafiadas e, realizados também de forma aleatória, os testes com fluido de corte.

As pontas de corte foram preparadas em uma afiadora universal $\mathrm{e}$, antes de serem realizados os ensaios de usinagem, elas foram fotografadas com microscópio digital e os ângulos de folga da ferramenta foram medidos com o auxílio do software Imagej. Na Tabela I, são apresentados os resultados, em que ângulo de folga de "referência" é o 
valor ajustado na afiadora e ângulo de folga "medido" é o valor obtido com as medições.

A execução de cada ensaio consiste no deslocamento da ferramenta de corte do furo central para a periferia do

Tabela I. Ângulos de folga de referência e medido

\begin{tabular}{cccc}
\hline $\begin{array}{c}\text { Ângulo } \\
\text { de folga } \\
\text { (referência) }\end{array}$ & Ângulo de folga (medido) & Fluído de \\
\cline { 2 - 3 } corte \\
\hline $2^{\circ}$ & $2,1^{\circ}$ & $2,5^{\circ}$ & Sem fluído \\
& $1,6^{\circ}$ & $1,3^{\circ}$ & Com fluído \\
$4^{\circ}$ & $5,2^{\circ}$ & $5,4^{\circ}$ & Sem fluído \\
& $5,1^{\circ}$ & $4,7^{\circ}$ & Com fluído \\
$6^{\circ}$ & $7,3^{\circ}$ & $7,0^{\circ}$ & Sem fluído \\
& $6,5^{\circ}$ & $6,5^{\circ}$ & Com fluído \\
$8^{\circ}$ & $8,1^{\circ}$ & $7,5^{\circ}$ & Sem fluído \\
& $9,5^{\circ}$ & $9,3^{\circ}$ & Com fluído \\
$10^{\circ}$ & $10,2^{\circ}$ & $10,0^{\circ}$ & Sem fluído \\
& $10,2^{\circ}$ & $10,2^{\circ}$ & Com fluído \\
\hline
\end{tabular}

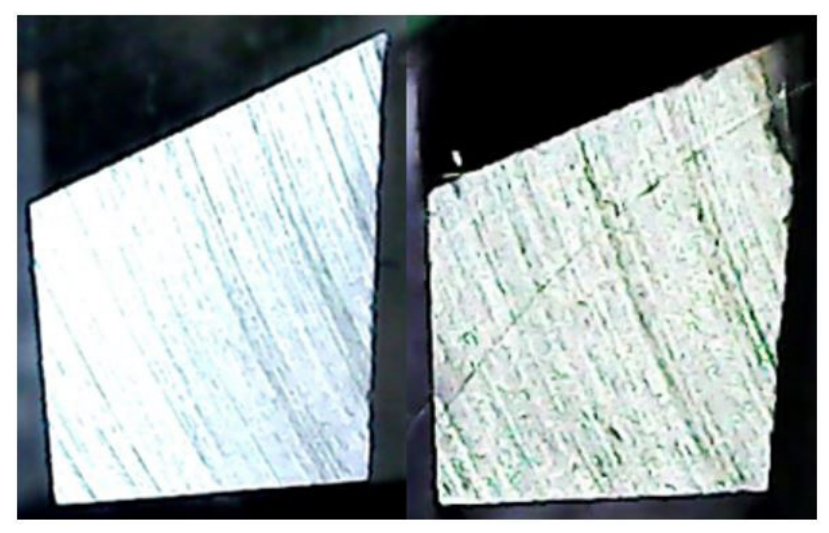

Figura 3. Ferramenta de aço rápido nova (esquerda) e desgastada (direita). disco, com avanço e rotação constantes, produzindo uma velocidade de corte uniformemente variada, decorrente do aumento do diâmetro de referência. Esse aumento da velocidade de corte faz com que a ferramenta vá se desgastando durante o trajeto até atingir um ponto de colapso, encerrando então o corte. Na Figura 3, é apresentada de forma ilustrativa uma imagem de uma ponta nova (antes do teste) e uma ponta desgastada (após o teste).

Quando o desgaste na ferramenta acontece, a profundidade efetiva de corte diminui o que causa uma marca na superfície faceada, tornando fácil a determinação do ponto de falha (Figura 4a). Para tornar a identificação do ponto de falha mais precisa, a profundidade efetivamente cortada foi medida com um relógio comparador. Para tanto, um relógio comparador, com resolução de $0,01 \mathrm{~mm}$, foi fixado no carro porta-ferramenta do torno (Figura 4b) e uma leitura superior a $0,1 \mathrm{~mm}$ foi adotado como critério para identificar o ponto de falha. A partir deste ponto, foi determinado o diâmetro de falha, que, posteriormente, foi medido com um paquímetro com resolução de 0,05 mm.

Este procedimento foi realizado com e sem fluido de corte a fim de analisar a influência deste na vida da ferramenta. Nos testes com fluido foi usado o óleo solúvel semissintético ecológico ME-I da Quimatic/Tapmatic, diluído em água na proporção I/19, aplicado na forma de jorro com vazão de 2,67 litros/minuto.

Para calcular a velocidade de corte na falha, utilizou-se a Equação I:

$$
\mathrm{Vc}_{\text {falha }}=\frac{\pi \cdot\left(\mathrm{d}_{\mathrm{usi}}\right) \cdot \mathrm{n}}{1000}
$$

sendo: $\mathrm{Vc}_{\text {falha }}=$ velocidade de corte na falha $(\mathrm{m} / \mathrm{min})$; $\mathrm{d}_{\text {usi }}=$ diâmetro usinado até a falha $(\mathrm{mm}) ; \mathrm{n}=\operatorname{rotação~}(\mathrm{rpm})$.

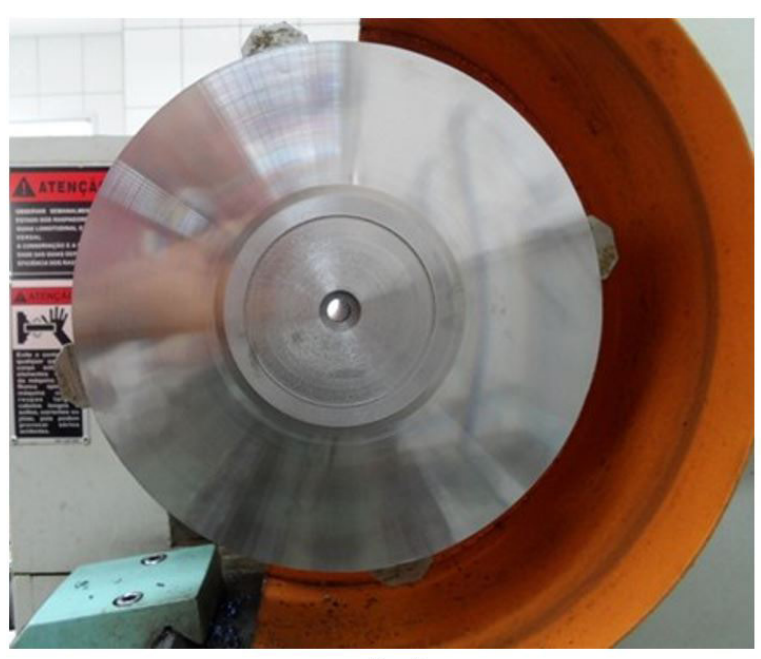

(a)

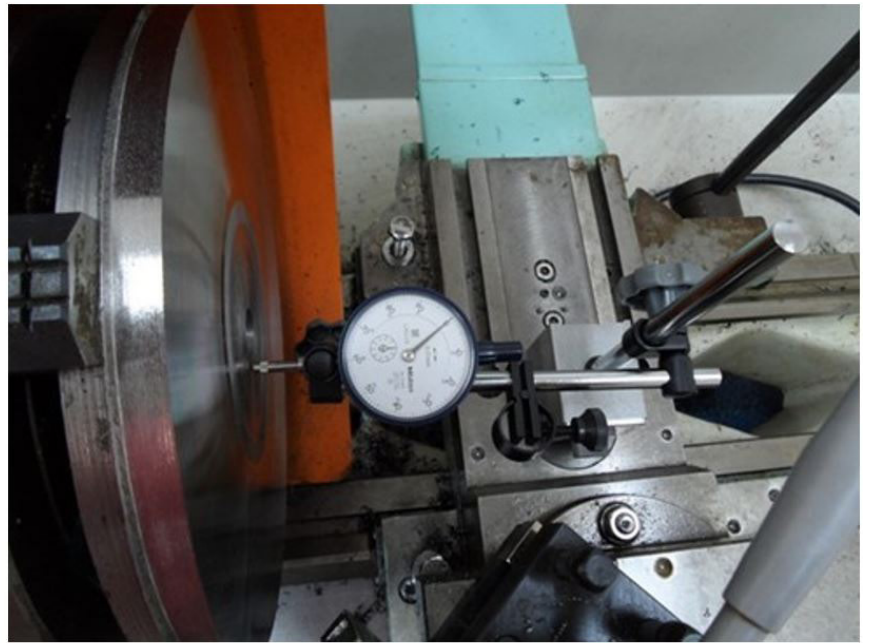

(b)

Figura 4. (a) Vista frontal da face torneada, (b) vista superior da face torneada com destaque ao posicionamento do relógio comparador. 


\section{RESULTADOS E DISCUSSÃO}

Após a realização do conjunto de vinte experimentos descritos na metodologia, dez sem fluido de corte e dez com fluido de corte, os resultados obtidos estão apresentados nas Tabelas 2 e 3 , respectivamente para os ensaios sem fluido de corte e com fluido de corte. Para ambas as tabelas, o valor da velocidade de corte no ponto de falha foi calculado com o auxílio da Equação I. O diâmetro usinado corresponde a duas vezes o percurso da ferramenta até o ponto de falha mais o diâmetro inicial do furo $(19,7 \mathrm{~mm})$.

Para facilitar a interpretação dos dados apresentados nas Tabelas 2 e 3, os resultados de percurso da ferramenta até o surgimento da falha, para as condições com fluido e sem fluido de corte, em função do ângulo de folga estão dispostos no gráfico da Figura 5. Os gráficos de diâmetro usinado e velocidade de corte no ponto de falha não serão apresentados porque apresentam o mesmo comportamento da Figura 5 , já que os valores são dependentes.

A partir dos resultados do gráfico da Figura 5 , exceto para $\circ$ ângulo de folga de $6^{\circ}$ (que em função dos desvios padrões apresentados, os resultados são similares), pode-se observar que, a presença do fluido de corte permite um maior percurso da ferramenta até que a mesma apresente falha. Este comportamento pode ser explicado pela ação lubrificante e refrigerante do fluido de corte. Como lubrificante, o fluido de corte reduz o atrito entre a ferramenta e a peça, consequentemente, reduz o desgaste e permite que a ferramenta permaneça usinando por um percurso maior. Como refrigerante, provavelmente, o fluido de corte reduz a temperatura da interface ferramenta-peça, que também contribui para uma maior vida da ferramenta.

Ainda pela mesma figura, percebe-se que o ângulo de $2^{\circ}$ apresenta $\circ$ menor percurso da ferramenta até $\circ$ aparecimento da falha em ambos os testes, o que pode ser explicado devido ao fato de possuir maior área de atrito entre a ferramenta e a peça. A partir do ângulo de $2^{\circ}$, as duas curvas apresentam a tendência inicial de aumento do percurso com o aumento do ângulo de folga até $6^{\circ} \mathrm{sem}$ fluido de corte e até $4^{\circ} \mathrm{com}$ fluido de corte. Essa tendência pode ser explicada pela redução na área de contato entre a ferramenta e a peça. Após esses pontos, ambas as curvas apresentam uma leve tendência de redução do percurso de corte nos pontos de $8^{\circ}$ e $6^{\circ}$, respectivamente sem fluido e com fluido de corte e, após estes pontos, o percurso volta a aumentar com o aumento do ângulo de folga.

Reis [14] usinando o Aço ABNT 1045 em consições similares, com fluido em jorro e ângulo de saída de $15^{\circ}$ (neste trabalho foi utilizado $18^{\circ}$ ) obteve este mesmo comportamento do gráfico, o que já não ocorreu quando o mesmo autor usinou com ângulos de saida menores. No entanto, o trabalho não apresenta evidencia suficiente para explicar o fenômeno.
O que pode ser argumentado é que o aumento no ângulo de folga provavelmente contribui no sentido de reduzir $o$ atrito e, consequentemente, aumentar $\circ$

Tabela 2. Velocidade de corte no ponto de falha em função do ângulo de folga da ferramenta sem aplicação de fluido de corte

\begin{tabular}{cccc}
\hline $\begin{array}{c}\text { Ângulo de } \\
\text { folga da } \\
\text { Ferramenta }\end{array}$ & $\begin{array}{c}\text { Percurso da } \\
\text { ferramenta } \\
\text { até o ponto } \\
\text { de falha } \\
(\mathbf{m m})\end{array}$ & $\begin{array}{c}\text { Diâmetro } \\
\text { usinado }(\mathbf{m m})\end{array}$ & $\begin{array}{c}\text { Velocidade } \\
\text { de corte } \\
\text { no ponto } \\
\text { de falha } \\
\text { (m/min.) }\end{array}$ \\
\hline $2^{\circ}$ & 34,85 & 89,40 & 88,47 \\
$4^{\circ}$ & 32,65 & 85,00 & 84,11 \\
& 52,65 & 125,00 & 123,70 \\
$6^{\circ}$ & 52,15 & 124,00 & $122,7 \mid$ \\
& 60,40 & 140,50 & 139,03 \\
$8^{\circ}$ & 58,15 & 136,00 & 134,58 \\
& 54,65 & 129,00 & 127,65 \\
$10^{\circ}$ & 54,65 & 129,00 & 127,65 \\
& 60,15 & 140,00 & 138,54 \\
\hline
\end{tabular}

Tabela 3. Velocidade de corte no ponto de falha em função do ângulo de folga da ferramenta com aplicação de fluido de corte

\begin{tabular}{cccc}
\hline $\begin{array}{c}\text { Ângulo de } \\
\text { folga da } \\
\text { Ferramenta }\end{array}$ & $\begin{array}{c}\text { Percurso da } \\
\text { ferramenta } \\
\text { até o ponto } \\
\text { de falha } \\
(\mathbf{m m})\end{array}$ & $\begin{array}{c}\text { Diâmetro } \\
\text { usinado }(\mathbf{m m})\end{array}$ & $\begin{array}{c}\text { Velocidade } \\
\text { de corte } \\
\text { no ponto } \\
\text { de falha } \\
(\mathbf{m} / \mathbf{m i n} .)\end{array}$ \\
\hline $2^{\circ}$ & 56,15 & 125,00 & 123,70 \\
$4^{\circ}$ & 56,65 & 126,00 & 124,69 \\
& 65,15 & 143,00 & 141,51 \\
$6^{\circ}$ & 62,15 & 137,00 & 135,58 \\
& 57,15 & 127,00 & 125,68 \\
$8^{\circ}$ & 62,65 & 138,00 & 136,57 \\
& 67,65 & 148,00 & 146,46 \\
$10^{\circ}$ & 68,65 & 150,00 & 148,44 \\
& 71,90 & 156,50 & 154,87 \\
\hline & 72,85 & 158,40 & 156,75 \\
\hline
\end{tabular}

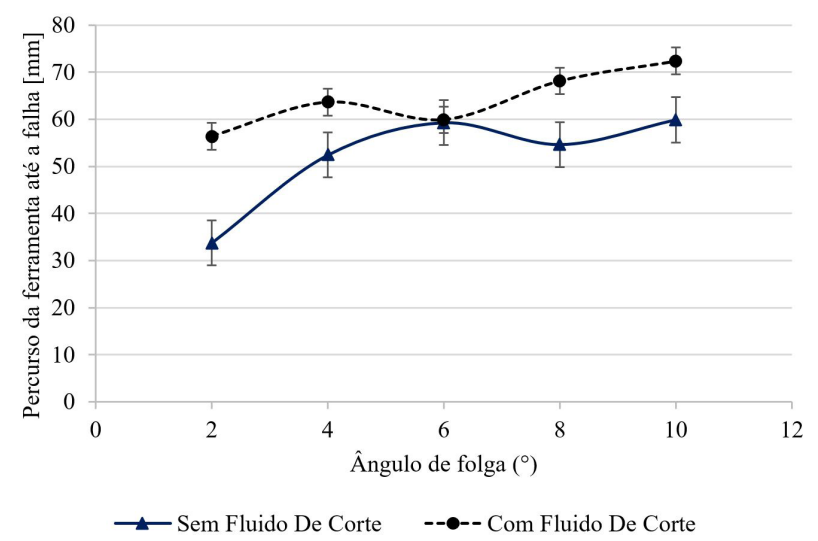

Figura 5. Relação do ângulo de folga versus percurso da ferramenta até a falha e uso de fluido de corte. 
percurso de corte. Mas por outro lado, o aumento do ângulo de folga para o mesmo ângulo de saída, torna a ponta da ferramenta mais fraca, contribuindo para reduzir o percurso de corte. Como os efeitos são contrários, isso pode explicar esta variação e a tendência de estabilização para valores mais altos.

\section{CONCLUSÕES}

Para as condições de testes e materiais utilizados neste trabalho, pode-se concluir que:

- Em função do maior atrito entre a superfície de folga e a peça e consequentemente maior aquecimento da ferramenta, o ângulo de folga de $2^{\circ}$ sem a aplicação de fluido de corte apresentou o pior resultado;
- A faixa avaliada, ângulo de folga entre $2^{\circ}$ e $10^{\circ}$, apresentou uma tendência geral de aumentar do percurso usinado com o aumento do ângulo de folga;

- A tendência de aumento do percurso usinado é mais pronunciada para os ângulos menores;

- O aumento no ângulo de folga parece contribuir no sentido de reduzir o atrito e, consequentemente, aumentar o percurso de corte, mas por outro lado, enfraquece a ponta da ferramenta. Como os efeitos são contrários, explica a tendência de estabilização para valores mais altos;

- A presença do fluido de corte aumenta o percurso usinado, com excessão ao ângulo de $6^{\circ}$, que se manteve inalterado.

\section{REFERÊNCIAS}

I Trent EM, Wright PK. Metal cutting. 4th ed. Boston: Butterworth Heinemann; 2000. 446 p.

2 Ferraresi D. Fundamentos da usinagem dos metais. São Paulo: Edgard Blucher; 1970. p. 566-645.

3 Diniz AE, Marcondes FC, Coppini NL. Tecnologia da usinagem dos materiais. 6. ed. São Paulo: Artliber; 2008.

4 Silveira J. Influência de fatores metalúrgicos na usinabilidade de ferros fundidos, FE 6002 e FE 4212 [dissertação]. Campinas: Faculdade de Engenharia Mecênica, Universidade Estadual de Campinas; 1983.

5 Pereira JCC. Determinação de modelos de vida de ferramenta e rugosidade no torneamento do aço ABNT 52100 endurecido utilizando a metodologia de superfície de resposta (DOE) [dissertação]. Itajubá: Curso de Engenharia Mecânica, Universidade Federal de Itajubá; 2006.

6 Oliveira JFG, Alves SM. Adequação ambiental dos processos de usinagem utilizando Produção mais Limpa como estratégia de gestão ambiental. Produção. 2007; 17:129-138.

7 Araujo AC, Mougo AL, Campos FO. Micro milling cutting forces on machining aluminium alloy. ICOMM; 2013.

8 Chieco NW. Apostila usinagem em maquinas convencionais. I. ed. 1998. p. 35.

9 Machado AR, Abrão AM, Coelho RT, Silva MB. Teoria da usinagem dos metais. São Paulo: Blucher; 2009.

10 Wertheim R, Satran A, Ber A. Modifications of the edge geometry and chip and chip formation in milling. CIRP Annals Manufacturing Technology. 1994;43(I):63-68. http://dx.doi.org/10.1016/S0007-8506(07)62165-9.

I I Kaldor S, Malkin S. A common denominator for optimal cutting tool geometry. CIRP Annals Manufacturing Technology. 1986;35(I):4I-44. http://dx.doi.org/10.1016/S0007-8506(07)6I834-4.

12 Cui X, Zhao J, Zhou Y, Zheng G. Damage mechanics analysis of failure mechanisms for ceramic cutting tools in intermittent turning. European Journal of Mechanics. A, Solids. 2013;37:139-149. http://dx.doi.org/10.1016/j. euromechsol.2012.06.002.

13 Araujo AS Jr, Machado AR, Silva MB, Neves TES, Rodrigues JRP. Estudo da usinabilidade do aço ABNT 1020 usando o método de faceamento rápido de brandsma. In: Associação Brasileira de Engenharia e Ciências Mecânicas (ABCM). Anais do $6^{\circ}$ Congresso Brasileiro de Engenharia de Fabricação (COBEF); 20II Abril II-I5; Caxias do Sul, RS. Rio de Janeiro: ABCM; 2011 .

14 Reis R. Estudo da influência da geometria da cunha da ferramenta de aço rápido na usinagem do aço ABNT 1045 em diferentes condições lubri-refrigerantes [dissertação]. Uberlândia: Universidade Federal de Uberlândia; 2015.

Recebido em: 07 Jul. 2017

Aceito em: 16 Out. 2018 